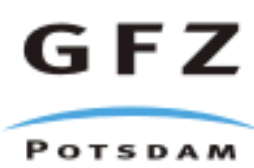

Originally published as:

Kumar, P., Yuan, X., Kumar, M. R., Kind, R., Li, X., Chadha, R. K. (2007): The rapid drift of the Indian tectonic plate. - Nature, 449, 894-897

DOI:10.1038/nature06214. 


\section{The Rapid Drift of the Indian Tectonic Plate}

Prakash Kumar ${ }^{1}$, Xiaohui Yuan², M. Ravi Kumar', Rainer Kind ${ }^{2,3}$, Xueqing Li $^{2}$ \& R. K. Chadha ${ }^{1}$

${ }^{1}$ National Geophysical Research Institute, Hyderabad, India

${ }^{2}$ GeoForschungsZentrum, Potsdam, Germany

${ }^{3}$ Freie Universität, Berlin, Germany

The breakup of the supercontinent Gondwanaland into Africa, Antarctica, Australia and India about 140 million years ago and consequently the opening of the Indian Ocean was caused by heating of the lithosphere from below by a large plume whose relicts are the Marion, Kerguelen and Reunion plumes. Plate reconstructions based on paleomagnetic data suggest that the Indian plate attained a very high speed (18-20 cm/yr during late Cretaceous) subsequent to its breakup from the Gondwanaland and slowed down to $\sim 5 \mathrm{~cm} / \mathrm{yr}$ since the continental collision with Asia during the last $\sim 50 \mathrm{Ma}^{1,2}$. The Australian and African plates moved comparatively lesser distances and at much lesser speed of $2-4 \mathrm{~cm} / \mathrm{yr}^{3,4,5}$. Antarctica remained almost stationary. This super mobility makes India unique compared to the other fragments of Gondwanaland. We propose that when the parts of Gondwanaland were separated by the plume, the penetration of their lithospheric roots into the asthenosphere played an important role in determining their speed. We estimated the thickness of the lithospheric plates of the different parts of Gondwanaland around the Indian Ocean using the S-receiver function technique. We found that the part of Gondwanaland with clearly the thinnest lithosphere has travelled with the highest speed - India. The lithospheric root in South Africa, Australia and Antarctica is between 180 and $300 \mathrm{~km}$ deep. The Indian lithosphere is in contrast only about $100 \mathrm{~km}$ thick (see Figure 1). Our interpretation is that the plume that partitioned Gondwanaland has also melted 


\section{the lower half of the Indian lithosphere thus permitting faster motion due to the ridge push or slab pull.}

The term lithosphere, commonly understood as the rigid outer shell of our planet Earth, floating on a viscous asthenosphere, originally evolved in a mechanical $\operatorname{sense}^{6}$ to explain the post-glacial rebound phenomenon. Since then, a number of usages of this term came into being, such as thermal, chemical, seismic lithospheres ${ }^{7}$. Traditionally, seismologists refer to this boundary as the Gutenberg discontinuity after the discovery of low velocity zones in regions underlying oceanic basins by Gutenberg ${ }^{8}$. Old and stable continental regions are understood to be underlain by a thick lithosphere ${ }^{9}$, as testified by the presence of numerous diamondiferous regions located within their interiors. Results from seismic tomography do bring out the presence of deep roots in old continents like Africa where the lithospheric thickness values exceed $250 \mathrm{~km}^{10}$.

Alterations of the primordial lithospheric configuration due to passage over hotspots in areas covered by vast regions of basalt on the continent (large igneous provinces) are also brought out in terms of thinning of the lithosphere and presence of low velocity uppermost mantle. As the thickness of the lithosphere plays a prominent role in shielding the mantle attrition processes that are so vital for determination of the stability factor for survival of the Precambrian crust, its precise determination becomes important. Also, imprints of major tectonic events like passage over hotspots (plume lithosphere interaction), rifting due to continental breakup, continental collision are expected to be manifested as alterations in the deep lithospheric architecture.

We apply a recently developed seismic method ( $\mathrm{S}$ receiver functions) to determine with high accuracy the depth of the lithosphere-asthenosphere boundary (LAB) in the region of the Indian Ocean and the surrounding fragments of Gondwanaland. Figure S1 and also Figure 1 show the distribution of the seismic stations used. This method utilizes S-to-P converted waves from the LAB beneath a 
seismic station. Details of the technique and examples of applications in other regions are given by a number of papers ${ }^{11-18}$. The observed $\mathrm{S}$ receiver functions are shown in Fig. 2a for each station. These data are summation traces of several tens of records at each station. Two prominent phases are clearly visible at all stations, marked Moho and LAB. In order to verify our observations of the LAB, we have discussed in the Supplementary Figure S3 individual S receiver functions at station Hyderabad (HYB) and their relation to possible anisotropy in the mantle and to $\mathrm{P}$ receiver function observations. Individual S receiver functions of HYB and three other Indian stations are also shown in the Supplementary Figures S4 and S5.

Conversions from the Moho and the LAB have different signs because they result from discontinuities with downward increasing (Moho) and decreasing (LAB) velocities. The times of the Moho vary between about 2 and $8 \mathrm{~s}$, those of the LAB vary between about 4 and $32 \mathrm{~s}$. The Moho and LAB times along with their corresponding depths (using the global reference model IASP91) are given in Supplementary Table S1. The stations in Fig. 2a are sorted with increasing order of LAB times. The depth of the LAB varies between 30 and $300 \mathrm{~km}$. There is no obvious correlation between crustal thickness and LAB depth. Theoretical receiver functions are shown in Figure $2 b$ for the models in Fig. 2c. The agreement between computed and observed seismograms is very good. A simple model with a homogeneous crust and a homogeneous lithosphere above the asthenosphere can explain most features of the observations. Only the depths of the Moho and of the LAB need to be varied. In this study we have not attempted to model the sharpness of the discontinuities. However, the relative amplitudes of the Moho and LAB phases with respect to their corresponding direct S-phases clearly reveal that the amplitude at Moho is 2 to 3 times larger than that for LAB. An interesting feature of Figure $2 \mathrm{~d}$ is that the cratonization of the lithosphere is reflected in a reduction of the LAB amplitudes whereas the Moho amplitudes remain nearly stable from oceanic regions to cratons. 
For verification that a large $\mathrm{LAB}$ time corresponds to a thick high-velocity mantle lid, we have looked at the arrival times of the P-to-S converted waves from the 410 discontinuity which roughly sample the average velocity above $410 \mathrm{~km}$ depth. The existence of a thick high-velocity lid can cause the converted waves to travel faster proportionally with the lid thickness. Consequently, the times of the P-to-S converted waves from the 410 should anti-correlate with the times of the S-to-P conversions from the LAB. In Figure 3 we show the measured times of the LAB, the 410 and 660. The waveform data of the 410 and 660 conversions are shown in Figure S3. Figure 3 shows clearly that the times of the LAB and 410 are anti-correlated, while those of the 410 and 660 are correlated. Small LAB depths correlate with low average velocities above the 410. The correlation of the 410 and 660 times suggests that most of the time variations can be attributed to mantle velocity variation above $410 \mathrm{~km}$ depth. The possible influence of the 410 topography on this conclusion is small ${ }^{19}$.

As shown in Figure 1, based on the data given in Figure 2a and Table S1, the lithosphere is very thin in the young regions of the mid-oceanic ridges and is very thick (more than $180 \mathrm{~km}$ ) below the cratons of South Africa, Antarctica and Australia. The Indian lithosphere is about $100 \mathrm{~km}$ thick or less, although it was a part of the same Gondwanaland. Six stations on the Indian shield namely DHD (situated on the western Dharwar craton), HYB \& CUD (situated on the Eastern Dharwar craton), KGD (situated within the Godavari rift zone), and BHPL and BOKR in northern India, indicate a lithospheric thickness of $80-100 \mathrm{~km}$. Such a thin lithosphere for the Indian shield is both unexpected and intriguing, since all these stations are sited on Archaean basement, away from the coast. Earlier studies of the lithospheric thickness in India do not lead to a homogeneous picture. Surface wave tomography studies reveal that the lithosphere could be about $100 \mathrm{~km}^{20}$ or $150 \mathrm{~km}^{21}$ thick. Lithospheric thickness estimates based on temperature-depth profiles ${ }^{22}$ yield an average value of $104 \mathrm{~km}$ for the Indian shield region. Studies based on temperature data constrained by P-T estimates from 
xenoliths lead to $200-250 \mathrm{~km}^{23}$ or $160 \mathrm{~km}^{24}$ (adding $\mathrm{S}$ velocity data) thickness. Our lithospheric thickness estimates are purely based on the seismic body wave observations, yielding the present day lithospheric thickness. We also think that the resolution of our body wave data is higher than that of the long period surface wave data. The lithosphere in the south Indian shield must have been originally thick, in view of the presence of diamond bearing Kimberlites ${ }^{24}$ close to HYB. There is now an increasing utilization of structural and metamorphic P-T data, precise dating measurements and comparison of subsurface geophysical models to aid in paleo continent reconstructions with respect to Gondwanaland and Rodinia ${ }^{25}$. Diamonds originate in the deep roots of ancient continental blocks that extend into the diamond stability field beneath about $140 \mathrm{~km}$ and more. Ar-Ar dating of the Kimberlites in the Indian shield constrain their age to the Proterozoic era $\left(\sim 1091 \pm 20 \mathrm{Ma}^{26}\right)$. Since the diamonds are older than the Kimberlites that transport them to the surface, the lithosphere in this region must have been thicker prior to the break up of Gondwanaland (140 Ma).

The high speed attained by India during Cretaceous coupled with the present day estimates prompts us to argue that the originally thick lithosphere beneath India seems to have been preferentially thinned by a large plume either during or immediately after the Gondwana breakup at $\sim 130 \mathrm{Ma}^{2}$. Subsequently, the Indian plate could have been further degenerated by the influence of its passage over the hotspots and the large scale magmatic extrusions like Deccan and Rajmahal traps, although their role in thinning of the lithosphere cannot be ascertained. Os isotopic studies suggest lack of evidence for the involvement of the subcontinental mantle lithosphere in Rajmahal Basalts ${ }^{27}$, which seem to share a common origin with the Kerguelen lavas ${ }^{28}$. In Figure 4 is shown a reconstruction of Gondwanaland with the present day lithospheric thickness, which is exceptionally small beneath India and east Africa. The loss of the lithospheric roots might have been the reason for the Indian plate to attain a very high plate velocity of 20 
$\mathrm{cm} / \mathrm{yr}$, which is unusual for any continental lithospheric plate ${ }^{29}$. The plate speed resulting from either push caused by a hot mantle source or trench pull due to a cold downwelling slab, increases with a decrease in root depth ${ }^{30}$.

In the present study, the thickest lithosphere $(\sim 300 \mathrm{~km})$ is found in the oldest continental nuclei in the Kaapvaal craton (Figure S2), which is diamond bearing, implying that the lithosphere is preserved over Archaean times. The other stations in the Archaean Kaapvaal craton also indicate a thick lithosphere with values in excess of 250 $\mathrm{km}$. This result gets support from independent studies of seismic tomography ${ }^{10}$. As expected, the thickness of the lithosphere is also found by seismic tomography ${ }^{31}$ to be in excess of $200 \mathrm{~km}$ in the Australian and Antarctic shield regions. Tomographic inversion of teleseismic $P$ and $S$ travel times indicates that high-velocity lithosphere beneath the Tanzania Craton extends to a depth of at least $200 \mathrm{~km}$ and possibly to 300 or $350 \mathrm{~km}^{32}$. It may be noted that the lithosphere tends to get thinner in regions closer to the coast owing to the effect of rifting due to the breakup of Gondwanaland super continent.

\section{References}

1. Klootwijk, C.T., Gee, J.S., Peirce, J.W. \& Smith, G.M. An early India-Asia contact: Paleomagnetic constraints from Ninetyeast Ridge, ODP Leg 121. Geology 20, 395398 (1992).

2. Gaina, C., Müller, R. D., Brown, B. \& Ishihara, T. Breakup and early seafloor spreading between India and Antractica. Geophys. J. Int. 170, 151-169 (2007).

3. Veevers, J.J. Breakup of Australia and Antarctica estimated as mid-Cretaceous (95+5 Ma) from magnetic and seismic data at the continental margin. Earth Planet. Sci. Lett. 77, 91-99 (1986). 
4. Cande. S.C. \& Mutter, J. C. A revised identification of the oldest sea-floor spreading anomalies between Australia and Antarctica. Earth Planet. Sci. Lett. 58, 151-160 (1982).

5. Jacoby, W.R. Theories and hypotheses of global tectonics. In: Fuchs, K., Soffel, H. (Eds.), Landolt-Bornstein, New Series, Group V, vol. 2 (Geophysics of the Solid Earth, the Moon and the Planets), Springer-Verlag. Berlin-Heidelberg, Sub volume b, 298-369 (1985).

6. Barrell, J. The strength of the Earth's crust, J. Geol. 22, $680 \mathrm{ff}$ (1914).

7. Anderson, D. L. Lithosphere, asthenosphere, and perisphere. Rev. Geophys. 33, 125-149 (1995).

8. Gutenberg, B. Physics of the Earth's Interior. 240 pp., Elsevier, New York (1959).

9. Jordan, T.H. The continental tectosphere, Rev. of Geophysics and Space Physics. 13, $1-13(1975)$.

10. James, D. E., Fouch, M. J., VanDecar, J. C. \& van der Lee, S. Tectospheric structure beneath southern Africa. Geophys. Res. Lett. 28, 2485-2488 (2001).

11. Li, X., Kind, R., Yuan, X., Wölbern I. \& Hanka, W. Rejuvenation of the Lithosphere by the Hawaiian plume. Nature 427, 827-829 (2004).

12. Kumar, P., Kind, R., Hanka, W., Wylegalla, K., Reigber, Ch., Yuan, X., Wölbern, I., Schwintzer, P., Fleming, K., Dahl-Jensen, T., Larsen, T. B., Schweitzer, J., Priestley, K., Gudmundsson, O. \& Wolf, D. The Lithosphere-Asthenosphere Boundary in the North West Atlantic Region. Earth Planet. Sci. Lett. 236, 249-257 (2005).

13. Kumar, P., Yuan, X., Kind R. \& Kosarev, G. The lithosphere-asthenosphere boundary in the Tien Shan-Karakoram region from S receiver functions - evidence of continental subduction. Geophys. Res. Lett., 32 (2005). 
14. Kumar, P., Yuan, X., Kind, R. \& Ni J. Imaging the colliding Indian and Asian lithospheric plates beneath Tibet. J. Geophys. Res. 111, B06308, doi:10.1029/2005JB003930 (2006).

15. Sodoudi, F., Yuan, X., Liu, Q., Kind, R. \& Chen, J. Lithospheric thickness beneath the Dabie Shan, central eastern China from S receiver functions. Geophy. J. Int. 166, 1363-1367 (2006).

16. Angus, D. A., Wilson, D.C., Sandvol, E. \& Ni, J.F. Lithospheric structure of the Arabian and Eurasian collision zone in eastern Turkey from S-wave receiver functions. Geophys. J. Int. 166, 1335-1346 (2006).

17. Landes M., Ritter, J.R.R. \& Readman, P.W. Proto-Iceland plume caused thinning of Irish lithosphere. Earth Planet. Sci. Lett. 255, 32-40 (2007).

18. Li, X., Yuan, X \& Kind, R. The lithosphere-asthenosphere boundary beneath the western United States. Geophys. J. Int., 170, 700-710 (2007).

19. Li, X., Kind, R., Yuan, X., Sobolev, S. V., Hanka, W., Ramesh, D. S., Gu, Y. \& Dziewonski, A. M. Seismic observation of narrow plumes in the oceanic upper mantle. Geophys. Res. Lett. 30, 6 (2003).

20. Polet, J. \& Anderson, D. L. Depth extent of cratons as inferred from tomographic studies. Geology 23, 205-208 (1995).

21. Mitra, S., Priestley, K., Gaur, V.K. \& Rai, S.S. Shear-wave structure of the south Indian lithosphere from Rayleigh wave phase-velocity measurements. Bull. Seism. Soc. Am. 96, 1551-1559 (2006).

22. Pandey, O. P. \& Agarwal, P. K. Lithospheric Mantle Deformation beneath the Indian Cratons. J. Geology 107, 683-692 (1999). 
23. Artemieva, I. M. Global 1 degree $\mathrm{x} 1$ degree thermal model TC1 for the continental lithosphere: Implications for lithosphere secular evolution, Tectonophysics 416, 245277 (2006).

24. Priestley, K. \& McKenzie, D. The thermal structure of the lithosphere from shear velocities. Earth Planet. Sci. Lett. 244, 285-301 (2006).

25. Mezger, K. \& Cosca, M. A. The thermal history of the Eastern Ghats belt (India) as revealed by $\mathrm{U}-\mathrm{Pb}$ and ${ }^{40} \mathrm{Ar} /{ }^{39} \mathrm{Ar}$ dating of metamorphic and magmatic minerals: implications for the SWEAT correlation. Precambrian Res. 94, 251-271 (1999).

26. Kumar A., Padma Kumari, V. M., Dayal, A. M., Murty, D. S. N. \& Gopalan, K. Rb$\mathrm{Sr}$ ages of Proterozoic Kimberlites of India: evidence for contemporaneous emplacement. Precambrian Res. 62, 227-237 (1993).

27. Ingle, S., Scoates, J. S., Weis, D., Brügmann, G. \& Kent, R. W. Origin of Cretaceous continental tholeiites in southwestern Australia and eastern India: insights from Hf and Os isotopes. Chem. Geology, 209, 83-106 (2004).

28. Coffin, M., Pringle, M.S., Duncan, R.A., Gladczenko, T.P., Storey, M., Müller, R. D. \& Gahagan, L.A. Kerguelen Hotspot magma output since 130 Ma, J. Petrol., 43, 1121-1139 (2002).

29. Jurdy, D. M. \& Gordon, R. G. Global plate motions relative to the hotspots 64 to 56 Ma. J. Geophys. Res. 89, 9927-9936 (1984).

30. Gurnis, M., \& Torsvik, T. H. Rapid drift of large continents during the late Precambrian and Paleozoic: Paleomagnetic onstraints and dynamic models. Geology, 22, 1023-1026, 1994.

31. Gaherty, J. B., Mamoru, K. \& Jordan, T. H. Seismological structure of the upper mantle: a regional comparison of seismic layering. Phys. Earth Planet. Inter. 110, 21-41 (1999). 
32. Ritsema, J., A. A. Nyblade, Owens, T. J., Langston, C. A. \& VanDecar, J. C. Upper mantle seismic velocity structure beneath Tanzania, east Africa: Implications for the stability of cratonic lithosphere. J. Geophys. Res. 103, 98JB01274, B9, 21201 (1998).

33. Frederiksen, A.W. \& Bostock, M. G. Modelling teleseismic waves in dipping anisotropic structures. Geophys. J. Int. 141, 401-412 (2000).

\section{Supplementary Information on www.nature.com/nature.}

Acknowledgements This research was supported by the Deutsche Forschungsgemeinschaft. PK was supported by DAAD Fellowship under which part of this work has been carried out at GFZ. Director NGRI is thanked for his support. Seismic data of most of the stations are available through the open data archives of IRIS (http://www.iris.edu/), GEOFON (http://www.gfz-potsdam.de/geofon/) and GEOSCOPE (http://geoscope.ipgp.jussieu.fr/) and Indian stations are supported by Department of Science and Technology, India. Seismic data analysis has been done in SeismicHandler (K. Stammler). We are thankful to Jason Phipps Morgan, Larry Brown, David Eaton, Dietmar Mueller and an anonymous referee for helpful comments.

\section{Figures}




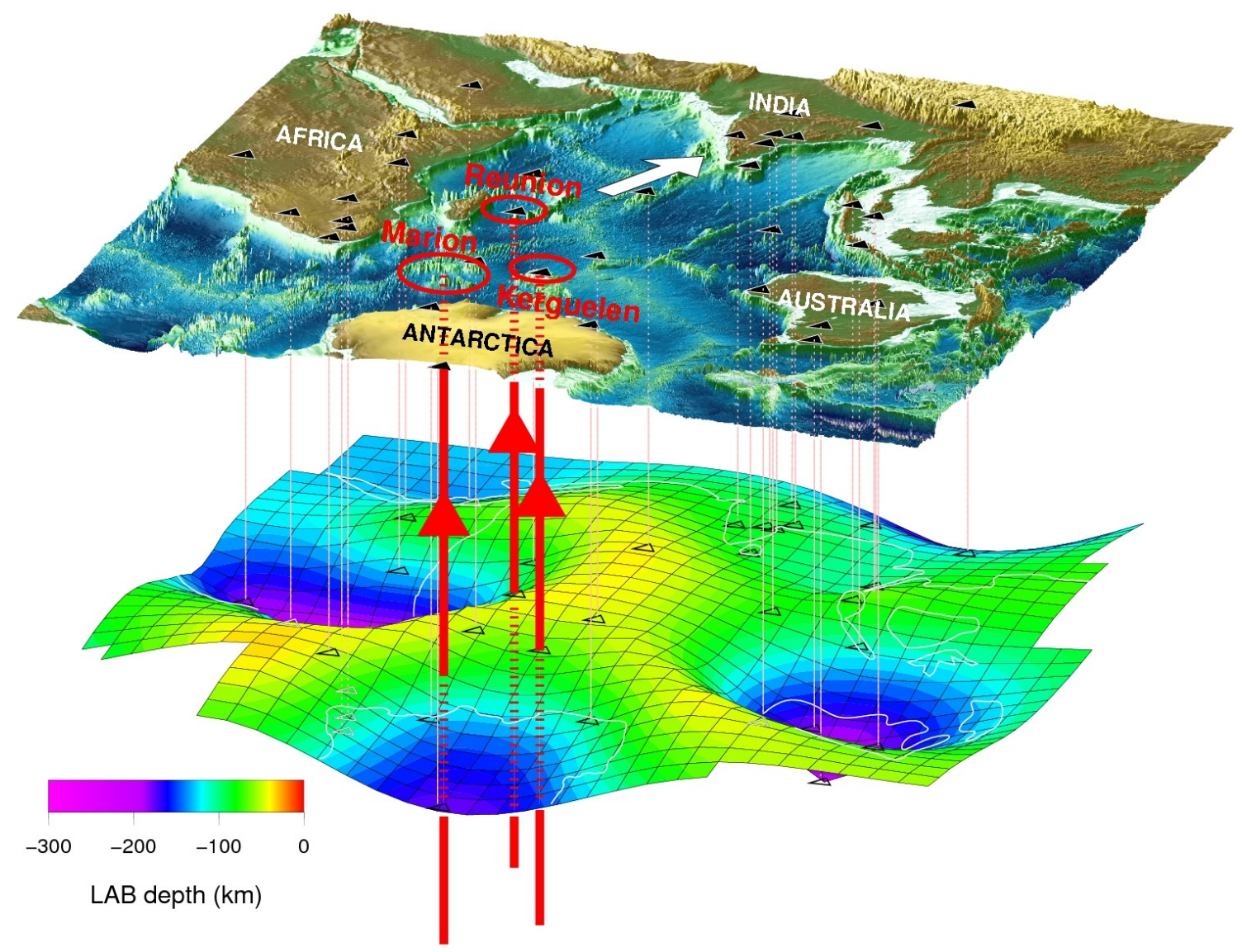

Figure 1: Topography of the surface and the lithosphere-asthenosphere boundary (LAB) in the region of the Indian Ocean and fragments of Gondwanaland surrounding it. The Indian lithosphere is exceptionally thin compared to the other parts of Gondwanaland. Black triangles denote seismic stations. The station locations are also shown in Figure S1 with station codes (Supplementary Figure S1). Red circles mark the surface locations of the mantle plumes whose conduits are illustrated by the thick vertical lines. 


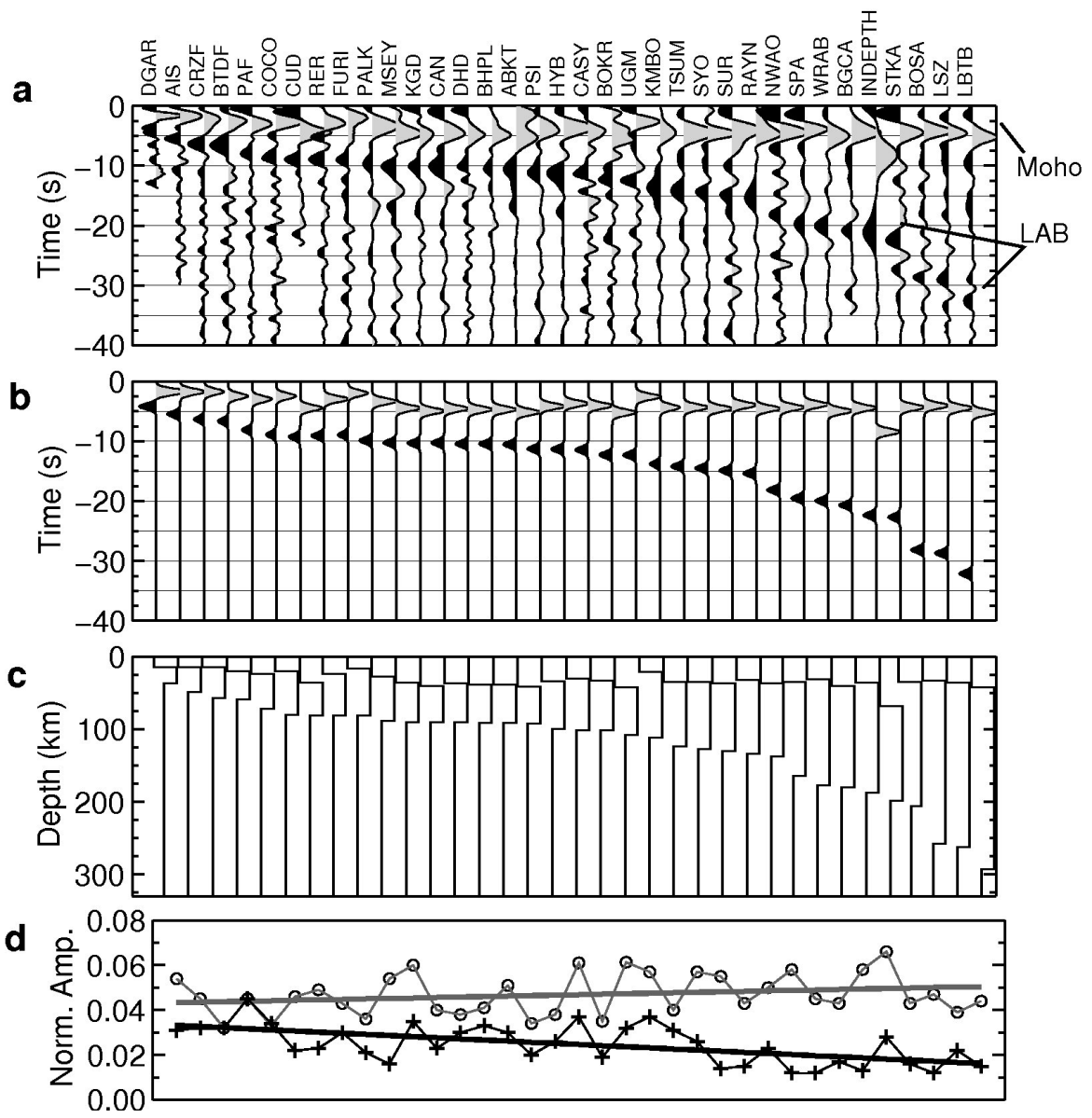

Figure 2: S-receiver function data and modeling. (a) Stacked S-receiver function traces from all stations used. Converted signals from the Moho and the LAB are clearly visible. The traces are arranged with the increasing LAB times. Vertical axis measures the time differences between the S-to-P converted phases and the corresponding reference $\mathrm{S}$ phases. Time is negative because the S-to-P converted waves travel faster than the $\mathrm{S}$ waves. (b) Synthetic seismograms ${ }^{33}$ which model the observed waveforms very well. (c) Simple models used for the computation of the theoretical seismograms. The models just consist of a homogeneous crust, mantle lithosphere and asthenosphere. Velocities are fixed for all the models (Vs crust $=3.58 \mathrm{~km} / \mathrm{s}$, Vs lithospheric mantle lid $=4.5 \mathrm{~km} / \mathrm{s}$, Vs asthenosphere $=3.9 \mathrm{~km} / \mathrm{s}$ ). Only the depths of both the discontinuities are varied to fit the travel times. (d) Variation of normalized amplitudes (with respect to direct S-phase) of the Moho (open circle) and the LAB (plus signs) with respect to the amplitude of direct S phase. Grey and black lines are the trend lines from least square fit. 


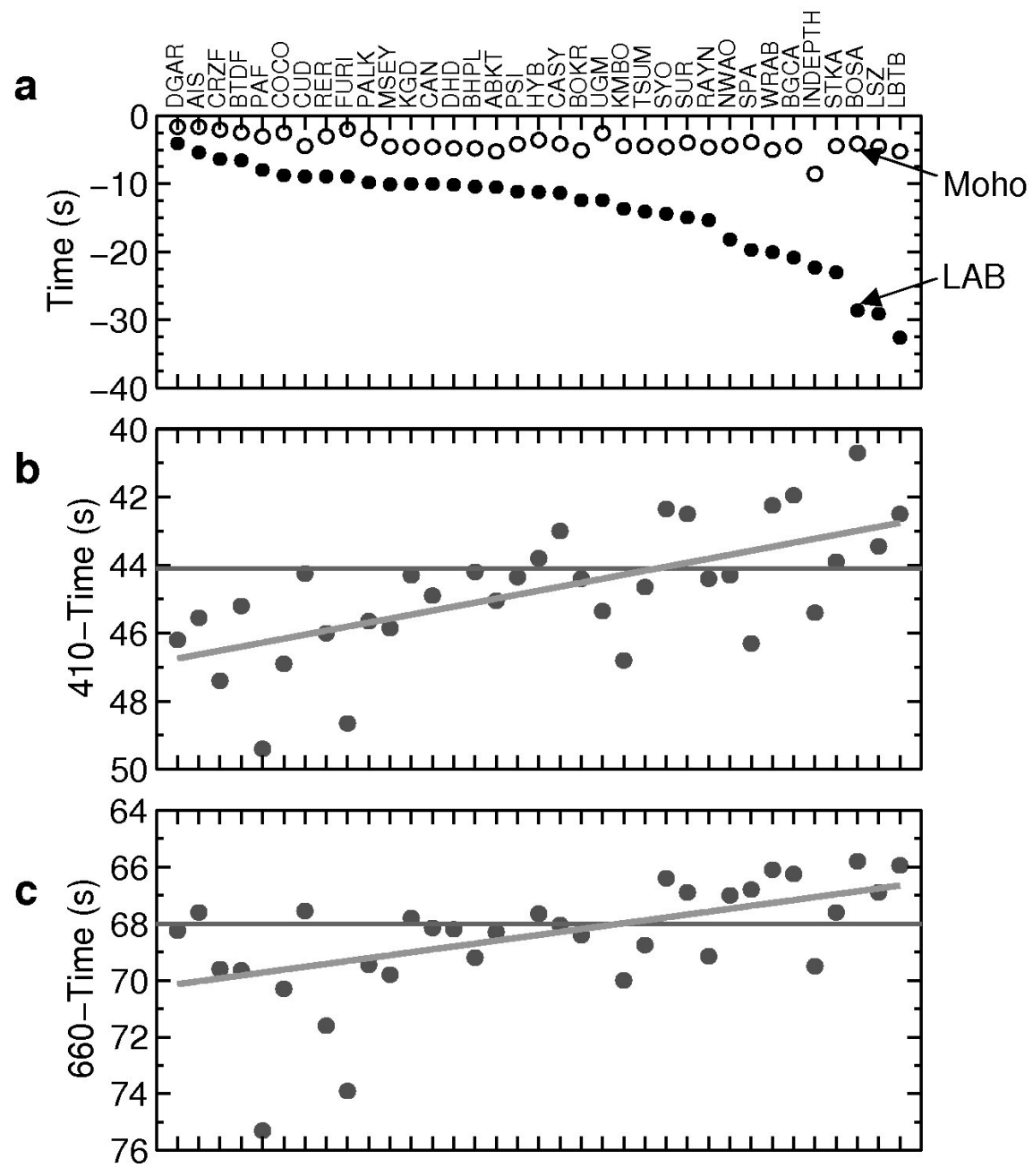

Figure 3: Comparison of different upper mantle seismic phases. (a) Solid black dots denote the times of the S-to-P conversions at the LAB arranged with increasing order and open circles are those of the Moho. (b) Times of the P-to-S converted waves at the 410. (c) Times of the P-to-S converted waves at the 660. As the LAB times (a) increase, the corresponding 410 (b) and 660 (c) times decrease. This observed anti-correlation confirms the interpretation of the LAB pulses as originating from the lithosphere-asthenosphere boundary. Scatterings in (b) and (c) are due to the time picking error and the presence of local heterogeneities within the upper mantle. 


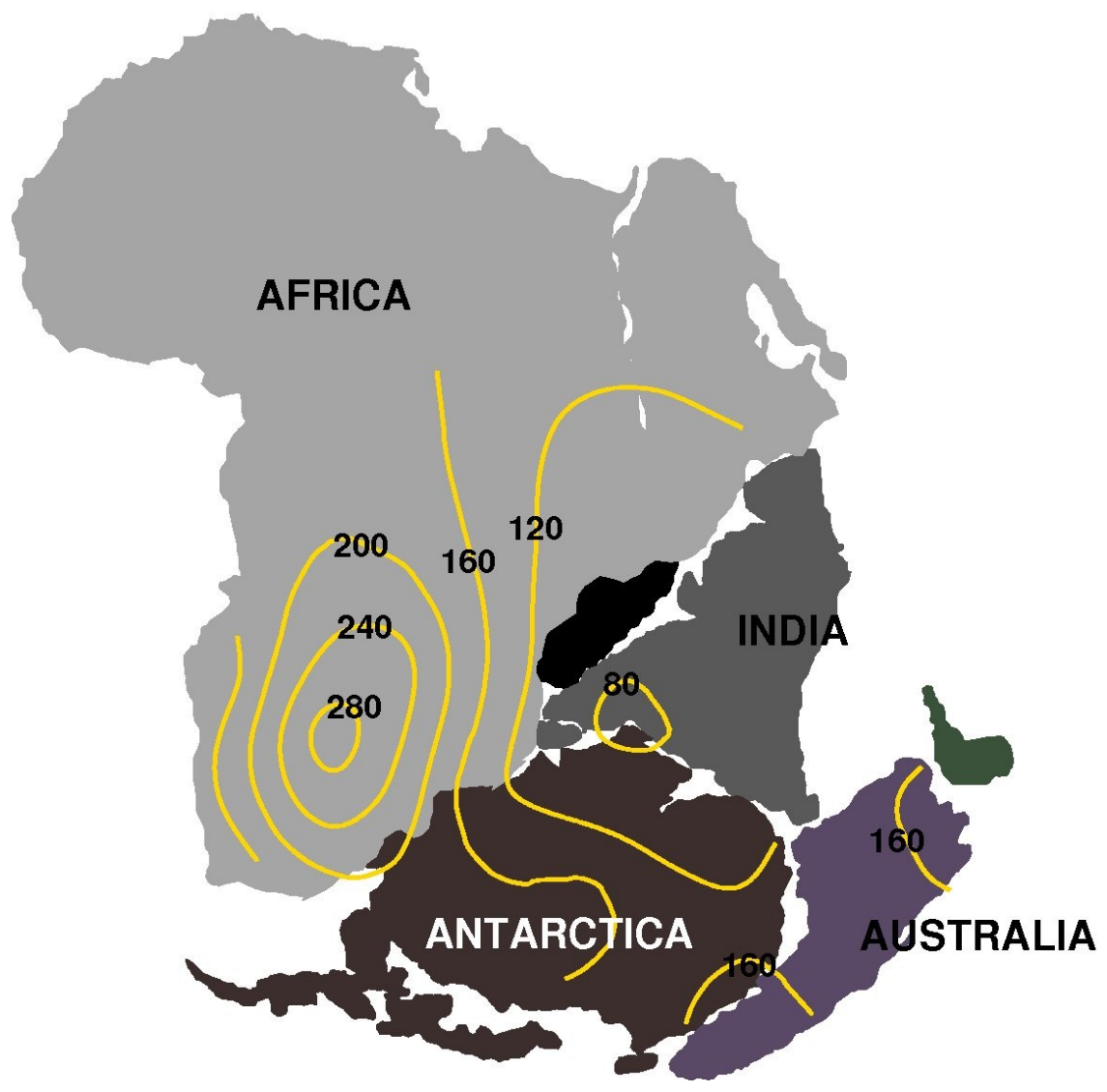

Figure 4: Reconstruction of the Gondwanaland at Permian. The contour denotes the present day lithospheric thicknesses in the continents. 